\title{
HUBUNGAN LAMA PENGGUNAAN GADGET DENGAN PERILAKU SOSIAL ANAK PRA SEKOLAH
}

\author{
Emri Oktaresa Putri, Agnita Utami, Raja Fitrina Lestari \\ Program Studi Keperawatan STIKes Hangtuah Pekanbaru \\ *penulis korespondensi, e-mail: emriputri@gmail.com \\ Dikirim 26 Februari 2020; Diterima 05 Maret 2020; Dipublikasikan Agustus 2020
}

\begin{abstract}
Gadgets are used by all people, including preschool children. The use of gadgets in the preschool increase every year and can make the child social behaviour is impaired because addicted to gadget duration play with more than 1 hour. This study aims to see the relationship between the use of gadgets and the social behaviour of preschool children. This type of research is quantitative using a description of correlation design with a cross-sectional approach. The sampling technique used was consecutive sampling with a sample of 76 respondents. Chi-square correlation test results obtained $=0.003(p<0.05)$, which means that there is a significant relationship between the duration of the use of gadgets and the social behaviour of preschool children in TK Negeri Pembina 3 Pekanbaru. The results of this study were expected to provide knowledge to parents who have preschool children to limit children in using gadgets. The data collection tool used is a questionnaire. The results of this study indicate that as many as $46.1 \%$ of children use gadgets more than 1 hour every day and $27.6 \%$ of children have bad socialization behaviour.
\end{abstract}

Keywords: Preschool Children, Gadgets, Social Behaviour

\section{PENDAHULUAN}

Teknologi pada saat ini semakin maju dan berkembang pesat. Teknologi yang paling berkembang pesat saat ini adalah gadget seperti smartphone, iPad dan iPod. Terdapat angka penggunaan gadget pada anak sekitar 38\% didunia. Pada tahun 2013 terjadi peningkatan anak usia dibawah delapan tahun didunia sebanyak $72 \%$ telah menggunakan perangkat mobile seperti smartphone, tablet dan ipad. Pada awalnya gadget hanya bisa dibeli oleh orang-orang yang berpenghasilan tinggi, namun sekarang orang yang berpenghasilan rendah juga sudah mampu membeli gadget (1). Selain itu banyak produsen-produsen gadget yang sengaja menjadikan anak-anak sebagai target pemasaran (2). Banyak orang tua yang memberikan gadget pada anaknya untuk permainan, hiburan dan Pendidikan (1).

Pemanfaatan gadget digunakan sebagian besar untuk bermain game dan menambah wawasan anak dari aplikasi yang ada pada gadget tersebut (3). Gadget pada masa sekarang mempunyai tampilan menarik yang diisi dengan aplikasiaplikasi yang menarik pula seperti game yang bervariasi mulai dari game berpetualangan sampai pelajaran. Desain yang dibuat semenarik mungkin membuat anak-anak merasa senang dan merasa terhibur menggunakannya (2).

Di Indonesia pada tahun 2011 tercatat penggunaan gadget pada anak usia 5 tahun yaitu sebesar 38\% terjadi peningkatan tahun 2015 yaitu 80\% (4). Anak lebih banyak menggunakan gadget sebagai sarana bermain (5). Diperkirakan Indonesia akan menjadi negara terbesar ke empat penggunaan gadget setelah Cina, India dan Amerika. Lembaga riset digital Marketing Emarketer memperkirakan pada tahun 2018 jumlah penggunaan gadget diperkirakan lebih dari 100 juta jiwa (2). 
Survei yang dilakukan oleh The Asianparent Insights tahun 2014, pada lingkup studi kawasan Asia Tenggara dengan melibatkan lebih kurang 2.417 orang tua yang mempunyai gadget dan anak yang berusia 3-8 tahun dengan jumlah 3,917 anak pada 5 negara yakni Singapura, Thailand, Philipina, Malaysia dan Indonesia. Didapatkan hasil 98\% anak-anak usia 3-8 tahun telah menggunakan gadget. Diantaranya 67\% menggunakan gadget orang tua, 18\% menggunakan gadget milik saudara atau keluarga dan 14\% menggunakan gadget milik sendiri (6). Terdapat $40(48,8 \%)$ dari 42 anak mengalami perkembangan sosial kurang dari rata-rata $(54,94 \%)$ yang cenderung memiliki kebiasaan bermain gadget lebih dari 1 kali sehari dengan waktu lebih dari 1 jam. Penggunaan gadget yang terlalu lama dapat mempengaruhi tingkat agresif anak dan membuat anak tidak peka terhadap lingkungan sekitar (7).

Anak yang berusia dibawah 18 bulan hindari penggunaan media layar selain dari obrolan video. Orang tua yang memiliki anak usia 18 hingga 24 bulan yang ingin memperkenalkan media digital kepada anak harus memilih program yang berkualitas tinggi dan didampingi pada saat anak-anak menggunakannya untuk membantu memahami apa yang mereka lihat. Anak usia 2-5 tahun harus dibatasi pengguaan gadget yaitu 1 jam perhari. Mendampingi anak menggunakan gadget selain untuk membantu anak memahami apa yang dilihat, juga dapat membantu anak untuk menerapkan dilingkungan sekitar anak. Anak yang berusia diatas 6 tahun, berikan batas yang konsisten dan pastikan gadget tidak menggangu tidur yang cukup, aktivitas fisik dan perilaku lain yang penting bagi Kesehatan (8).

Penggunaan gadget pada anak mempunyai dampak positif dan negatif. Dampak positif pada anak dapat mengasah keterampilan dan kecerdasan. Melalui aplikasi seperti aplikasi mewarnai, belajar membaca dan menulis. Hal ini membuat anak-anak sangat senang belajar karena aplikasi yang ada dilengkapi gambar-gambar dengan karakter yang menarik. Kemudian anak juga bisa berkomunikasi jarak jauh dengan teman sebaya ataupun keluarga (2). Dampak negatif dari penggunaan gadget yaitu kemudahan dalam mengakses informasi sehingga membuat anak-anak menjadi malas untuk bergerak dan melakukan aktivitas. Akibat penggunaan gadget secara berlebihan anak akan lupa kesenangan bermain dengan teman sebaya maupun dengan anggota keluarga. Hal ini akan berdampak sangat buruk untuk kesehatan dan perkembangan anak. Selain itu juga penggunaan gadget secara berlebihan bisa membuat interaksi sosial anak terganggu dan tidak perduli dengan lingkungan sekitar dan masyarakat (2).

Anak harus diberi pengalihan dari gadget agar interaksi anak dengan lingkungan sekitar tidak terganggu dengan cara memberikan permainan yang bisa meningkatkan perkembangan anak agar tidak terfokus pada gadget saja. Mengalihkan perhatian anak dari gadget perlu kegiatan-kegiatan yang bisa membuat perkembangan anak menjadi baik. Kegiatan bermain anak untuk mengalihkan perhatian anak dari gadget yaitu bermain aktif dan pasif. Kegiatan bermain aktif seperti bermain konstruksif yang menciptakan suatu hasil karya seperti menggambar, menciptakan suatu bentuk tertentu dari lilin mainan, menggunting dan menempel kertas ataupun menyusun puzzle (9).

Perhatian-perhatian khusus dari orang tua sangat dibutuhkan anak untuk mengoptimalkan pertumbuhannya. Terutama anak usia prasekolah yang mempunyai karakteristik tersendiri untuk persiapan menuju periode sekolah (10). Pada usia prasekolah ini terjadi aktivitas yang tinggi dan perkembangan fisik serta perkembangan kepribadian yang besar. Pada usia ini, perkembangan motorik juga berlangsung secara terus menerus. Masa kanak-kanak awal yang terlihat prilaku sosial anak adalah kerja sama antar teman sebaya atau dengan kelompok seperti kelompok bermain, persaingan, penerimaan sosial, simpati, empati, sikap ramah, ketergantungan, meniru dan sikap yang tidak hanya mementingkan diri sendiri namun juga orang lain (11). 
Penggunaan gadget pada anak usia 3-6 tahun mempunyai pengaruh terhadap psikososial anak usia prasekolah. Dengan menggunakan gadget dari batas yang telah ditetapkan, maka akan mempengaruhi interaksi sosial anak pada lingkungan sekitar (12). Hal ini dibuktikan dari penelitian terhadap anak PAUD/TK Islam Budi Mulia dengan sampel 47 orang terdapat $63 \%$ responden tidak normal dalam menggunakan gadget, 40,4\% responden perkembangannya menyimpang. Artinya terdapat hubungan penggunaan gadget dengan perkembangan anak usia prasekolah karena lamanya penggunaan gadget (13). Selain itu, berdasarkan hasil survey pendahuluan peneliti terhadap 3 orang tua anak di TK Negeri Pembina 3 Pekanbaru, mengatakan anak mereka suka bermain gadget lebih dari satu jam. Pada saat dipanggil anak juga cenderung lambat merespon ketika sedang bermain gadget. Dua anak diantaranya menggunakan gadget tanpa pengawasan orang tua. Anak cenderung menonton televisi dari pagi hingga siang, satu diantara dua anak tersebut, menggunakan smartphone orang tua untuk melihat video-video di youtube tanpa pengawasan orang tua dan orang tua tidak menentukan batas waktu pada anak, sehingga anak bisa bermain hingga lebih dari 1 jam sehari. Penggunaan gadget yang lama membuat orang tua mengeluhkan tentang anak-anak yang susah diingatkan, lupa waktu dan tidak memperdulikan lingkungan sekitar. Berdasarkan hal ini, peneliti tertarik meneliti tentang hubungan pengguaan gadget dengan perkembangan sosial pada anak usia prasekolah.

\section{METODE PENELITIAN}

Jenis penelitian ini adalah kuantitatif dengan desain penelitian deskripsi korelasi menggunakan pendekatan cross-sectional. Subjek penelitian yaitu anak usia pra sekolah program TK B di TK Negeri Pembina 3 Pekanbaru, namun informasi tentang anak terkait tujuan penelitian ini dikumpulkan dari orang tua siswa. Jumlah siswa terdiri dari 158 orang, yang terpilih sebagai sampel sebanyak 76 orang. Teknik dalam pengambilan sampel dengan teknik consecutive sampling yaitu berdasarkan kriteria bersedia mengisi kuesioner selama kurun waktu 2 minggu penelitian karena sekolah akan diliburkan selama bulan puasa Ramadhan. Teknik pengumpulan data dengan Angket menggunakan instrument Checklist. Peneliti kemudian melakukan pengolahan data melalui program komputer. Data dianalisis secara univariat dan bivariat dengan uji statistik Chi square.

\section{HASIL DAN PEMBAHASAN}

Karakteristik anak pra sekolah berdasarkan umur dan jenis kelamin anak dapat ditemukan pada tabel 1 berikut ini:

Tabel 1. Distribusi Frekuensi Karakteristik Responden

\begin{tabular}{clcc}
\hline No & Karakteristik Responden & Jumlah & $\begin{array}{c}\text { Persentase } \\
\text { (\%) }\end{array}$ \\
\hline $\mathbf{1}$ & Usia Anak & 7 & \\
& 4 tahun & 18 & 9,2 \\
& 5 tahun & 51 & 23,7 \\
& 6 tahun & $\mathbf{7 6 ~ o r a n g}$ & $\mathbf{1 0 0 \%}$ \\
\hline & Jumlah & & \\
\hline $\mathbf{2}$ & Jenis Kelamin Anak & 37 & 48,7 \\
& Laki-Laki & 39 & 51,3 \\
\hline & Perempuan & $\mathbf{7 6 ~ o r a n g}$ & $\mathbf{1 0 0} \%$ \\
\hline
\end{tabular}

Berdasarkan hasil penelitian di TK Negeri Pembina 3 Pekanbaru, subjek yang terbanyak $(67,1 \%)$ berusia 6 tahun. Perkembangan anak usia prasekolah tergolong dalam perkembangan yang pesat seperti perkembangan fisik, kognitif, emosi, motorik, sosial serta moral (14). Dari tabel 1 juga dapat dilihat, mayoritas jenis kelamin anak yang menggunakan gadget di TK Negeri 3 Pekanbaru adalah perempuan yaitu $39(51,3 \%)$ anak. Anak perempuan lebih banyak menggunakan gadget dari pada laki-laki karena perempuan relatif senang menggunakan fitur-fitur permainan gambar yang terdapat pada gadget (15). 
Pada tabel 2 menggambarkan jumlah waktu yang dihabiskan oleh anak pra sekolah dalam menggunakan gadget dalam sehari.

Tabel 2. Distribusi Frekuensi Responden Berdasarkan Lama Penggunaan Gadget per hari

\begin{tabular}{cccc}
\hline No & $\begin{array}{c}\text { Lama } \\
\text { Penggunaan } \\
\text { Gadget }\end{array}$ & Jumlah & $\begin{array}{c}\text { Persentase } \\
\text { (\%) }\end{array}$ \\
\hline $\mathbf{1}$ & $\leq 1$ jam & 41 & 53,9 \\
$\mathbf{2}$ & $>1$ jam & 35 & 46,1 \\
\hline & Jumlah & $\mathbf{7 6}$ orang & $\mathbf{1 0 0 \%}$ \\
\hline
\end{tabular}

Berdasarkan hasil penelitian di TK Negeri Pembina 3 Pekanbaru menunjukkan lebih dari separuh $(46,1 \%)$ anak bermain gadget kurang dari 1 jam. Pada penelitian di TK Islam Al Irsyad o1 Cilacap yaitu sebanyak 20 (37,7\%) anak menggunakan gadget dengan durasi lebih dari 1 jam dan 33 (63,3\%) anak menggunakan gadget kurang dari 1 jam (16). Sebanyak 24 anak dari 33 responden di TK Al-Marhama menggunakan smartphone lebih dari 1 jam (17). Orang tua harus memberikan batasan-batasan anak dalam penggunaan gadget setiap harinya. Menurut psikolog anak, batasan waktu dalam bermain gadget adalah 1 jam setiap hari dan hanya di hari libur seperti hari minggu. Orang tua harus selalu memantau apa yang dilihat anak pada saat bermain gadget (8). Saat ini banyak orang tua yang kurang peduli pada saat anak menggunakan gadget. Orang tua memberikan gadget pada anak agar anak mempunyai kegiatan dan tidak mengganggu pekerjaan orang tua (Indriyani, Sofia dan Anggraini, 2018). Berdasarkan hasil penelitian di TK Negeri Pembina 3 Pekanbaru mayoritas orang tua murid adalah orang tua yang bekerja yaitu sebanyak $52(68,4 \%)$ responden. Pekerjaan membuat orang tua tidak sepenuhnya bisa bermain dan berinteraksi dengan anak bahkan mengontrol anak dalam bermain gadget. Kurangnya waktu orang tua dalam pengalihan anak terhadap gadget. Semakin sibuk pekerjaan orang tua maka akan lebih sedikit pula waktu yang digunakan untuk mendidik dan menemani anak. Apabila hal itu terus dilakukan akibatnya anak akan menjadi kecanduan dalam penggunaan gadget (7).

Dilihat dari sebagian jawaban orang tua pada kuesioner, orang tua mengatakan bahwa anak terkadang marah apabila diganggu pada saat bermain gadget, anak selalu ingin terlihat pandai dalam bermain gadget, anak sering berselisih dengan teman atau keluarga akibat berebut gadget, anak tidak mendengarkan nasehat orang tua dan anak akan marah apabila dilarang bermain gadget meskipun sudah diberikan penjelasan dengan baik. Sebagai orang tua yang bekerja juga harus mampu memantau anak dalam penggunaan gadget.

Tabel 3. Perilaku Sosial Anak Berdasarkan Persepsi orang tuanya

\begin{tabular}{cccc}
\hline No & $\begin{array}{c}\text { Perilaku Sosial } \\
\text { Anak Prasekolah }\end{array}$ & Jumlah & Persentase (\%) \\
\hline $\mathbf{1}$ & Baik & 42 & 55,3 \\
$\mathbf{2}$ & Tidak Baik & 34 & 44,7 \\
\hline & Jumlah & $\mathbf{7 6}$ orang & $\mathbf{1 0 0} \%$ \\
\hline
\end{tabular}

Berdasarkan tabel 2 dan 3 mayoritas anak yang menggunakan gadget kurang dari 1 sebanyak $41(53,9 \%)$ responden dan 55,3\% memiliki perilaku sosial yang baik. Berdasarkan hasil penelitian di TK Negeri Pembina 3 Pekanbaru, dari 76 anak terdapat $34(44,7 \%)$ anak memilki perilaku sosial yang tidak baik. Perkembangan anak tergantung dari pola asuh dan kasih sayang orang tua. Anak yang mendapatkan kasih sayang dan pola asuh yang baik seperti memberikan anak rasa aman dan perlindungan, mengajarkan anak bagaimana cara berinteraksi dengan lingkungan sekitar maka perkembangan anak akan baik. 
Sebaliknya jika anak tidak mendapatkan kasih sayang dan perhatian dari orangtua maka akan terjadi penyimpangan perkembangan perilaku sosial anak seperti anak tidak perduli akan lingkungan sekitar dan lebih senang menyendiri (18). Terdapat pengaruh yang signifikan antara tingkat pendidikan orangtua dan pola asuh terhadap perkembangan anak. Tingkat pendidikan orangtua yang baik, disiplin dan bijaksana maka akan menghasilkan pola asuh yang lebih baik terhadap perkembangan anak. Orangtua yang berpendidikan tinggi akan memberikan pengetahuan dan membimbing anak (19). Hal ini sesuai dengan penelitian di TK Negeri Pembina 3 Pekanbaru bahwa mayoritas pendidikan terakhir orangtua yang paling banyak yaitu pendidikan tinggi sebanyak $56(73,7 \%)$ responden. Tingginya pendidikan orangtua murid membuat perilaku anak menjadi lebih baik. Hal ini sesuai dengan hasil penelitian perilaku sosial anak bahwa di TK Negeri Pembina 3 Pekanbaru terdapat anak yang mempunyai perilaku baik lebih banyak yaitu sebesar $42(55,3 \%)$ anak. Tingginya pendidikan orang tua maka perilaku anak akan berkembang baik karena orangtua yang memiliki pendidikan tinggi akan tahu bagaimana cara agar perilaku anak tidak menyimpang.

Sebagai orangtua atau pendidik perlu memberikan contoh yang baik seperti mengajarkan anak bersosialisasi dengan teman sebaya atau keluarga, mengajarkan anak sesuai usia perkembangannya, karena pada usia prasekolah anak akan meniru perilaku disekitarnya. Salah satu faktor perkembangan perilaku sosial anak adalah pemberian pola asuh. Pola asuh yang baik yaitu seperti memperhatikan perkembangan anak agar tidak terjadi penyimpangan dan memberikan bimbingan untuk perkembangan perilaku anak. Anak prasekolah perlu diberitahu tentang tugas yang harus dilakukan sesuai usia anak dan memberikan arahan yang benar agar perilaku sosial anak tidak menyimpang.

Tabel silang hasil dari hubungan antara penggunaan gadget dengan perilaku social responden tergambar dari tabel 4.

Tabel 4. Hubungan Lama Penggunaan Gadget dengan Perilaku Sosial Anak Berdasarkan Persepsi Orang tuanya

\begin{tabular}{|c|c|c|c|c|c|}
\hline \multirow[t]{2}{*}{ No } & \multirow{2}{*}{$\begin{array}{c}\text { Lama } \\
\text { Penggunaan } \\
\text { Gadget }\end{array}$} & \multicolumn{2}{|c|}{ Perilaku sosial } & \multirow[t]{2}{*}{ Total } & \multirow{2}{*}{$\begin{array}{c}\boldsymbol{P} \\
\text { value }\end{array}$} \\
\hline & & Baik & Tidak Baik & & \\
\hline 1 & $\leq 1 \mathrm{jam}$ & $29(38,2 \%)$ & $12(18,5 \%)$ & $41(53,9 \%)$ & \\
\hline \multirow[t]{2}{*}{2} & $>1$ jam & $13(17,1 \%)$ & $22(28,9 \%)$ & $35(46,1 \%)$ & o,003 \\
\hline & Jumlah & $42(55,3 \%)$ & $34(44,7 \%)$ & $76(100 \%)$ & \\
\hline
\end{tabular}

Berdasarkan tabel 4, Penggunaan gadget pada anak dengan durasi lebih dari 1 jam akan berdampak tidak baik pada perilaku sosial anak sebesar 28,9\%, persentase ini lebih besar jika dibanding menggunakan gadget kurang dari satu jam yakni 18,5\%. Hasil uji statistik menggunakan uji Chi-Square diperoleh $\boldsymbol{P}_{\text {value }}=0,003<\alpha$ $(0,05)$, hal ini menunjukkan adanya hubungan antara lama penggunaan gadget dengan perilaku sosial anak prasekolah di TK Negeri Pembina 3 Pekanbaru. Menurut orang tua siswa TK Negeri Pembina 3 Pekanbaru, terdapat perilaku sosial anak anak mereka yaitu pembangkang, marah ketika tidak diberikan gadget, lebih suka bermain dirumah dengan gadget dari pada diluar bersama teman sebaya atau keluarga, tidak aktif berbicara ketika bermain dengan teman-teman, tidak mendengarkan nasehat orang tua dan tidak kooperatif saat diajak bekerjasama.

Hasil penelitian ini sesuai dengan penelitian Gunawan (2017), dimana hasil penelitian diperoleh $P$ value yaitu $0,000<0,05$ yang artinya terdapat hubungan durasi penggunaan gadget terhadap perkembangan sosial anak prasekolah di TK PGRI 33 Sumurboto, Banyumanik. Penelitian tersebut menjelaskan bahwa 40 dari 42 anak yang sering menggunakan gadget memiliki perkembangan sosial yang tidak baik. 
Terdapat beberapa yang mempengaruhi perkembangan perilaku sosial anak prasekolah salah satunya adalah penggunaan gadget. Penggunaan gadget pada anak usia prasekolah seperti televisi, laptop, komputer, smartphone, iPad, iPod dan lain sebagainya hanya boleh digunakan 1 jam dalam sehari. Penggunaan gadget lebih dari 1 jam akan berdampak negative terhadap perkembangan perilaku sosial anak seperti dapat mempengaruhi peningkatan agresif pada anak. selain itu anak menjadi tidak peka terhadap lingkungan. Gadget membuat anak lupa berinteraksi dengan orang sekitar maupun keluarga dan penggunaan gadget yang terlalu lama membuat anak menjadi pribadi yang pembangkang dan tidak mendengarkan nasehat orang tua. Anak menjadi mudah marah apabila yang diinginkan anak seperti bermain gadget tidak dipenuhi oleh orang tua anak. Penggunaan gadget lebih dari 1 jam dapat mengganggu perkembangan perilaku sosial anak prasekolah karena gadget membuat anak jarang berkomunikasi dengan lingkungan. Gadget membuat anak tidak tahu bagaimana cara bersosialisasi dengan baik, anak juga tidak mampu mengenal emosi seperti simpati, sedih atau senang (3). Orangtua harus memperioritaskan waktu bermain anak dengan keluarga atau teman sebaya dari pada bermain menggunakan gadget agar interaksi anak dengan lingkungan sekitar menjadi baik (8).

Orangtua harus mempunyai motivasi dan pengetahuan tentang penggunaan gadget pada anak usia prasekolah. Anak harus diberi batasan waktu 1 jam dalam sehari untuk bermain gadget. Orangtua harus selektif dalam memilih permainan untuk anak agar tidak terjadi penyimpangan perilaku sosial. Perkembangan sosial anak prasekolah yaitu melakukan interaksi sosial baik dirumah maupun diluar rumah, melakukan komunikasi dengan orang dewasa seperti guru dan orang tua untuk menarik perhatian, anak selalu bermain dengan lingkungan sekitar baik orang dewasa atau teman sebaya, melakukan percakapan dan mengurangi tingkah laku bermusuhan, belajar bekerjasama dalam kelompok teman sebaya dan belajar menjadi pribadi yang mandiri (20).

\section{KESIMPULAN}

Hasil penelitian di terhadap anak TK Negeri Pembina 3 Pekanbaru, Penggunaan pada gadget lebih dari 1 jam mengakibatkan ia cenderung tidak peduli terhadap lingkungan sekitar, malas bergerak sehingga akan berdampak pada kesehatan fisik dan psikologis anak. Anak akan kesulitan dalam penyesuaian diri, kemandirian anak dalam berpikir dan berprilaku, mudah marah, tidak mau mendengarkan ketika dinasehati. Anak juga menjadi pembangkang, marah ketika tidak diberikan gadget, lebih suka bermain di rumah dengan gadget dari pada diluar bersama teman sebaya atau keluarga, tidak aktif berbicara ketika bermain dengan teman-teman, tidak mendengarkan nasehat orang tua dan tidak kooperatif saat diajak bekerjasama. Hasil uji statistik menunjukkan Pvalue $=0,003$ yang berarti adanya hubungan antara lama penggunaan gadget dengan perilaku social anak pra sekolah.

\section{DAFTAR PUSTAKA}

1. Fahrizal A. Smart Digital Parent, Tips dan Trik Gadget dan Dunia Online untuk para Orang Tua di Era Digital. Yogyakarta: Diandra Kreatif; 2018.

2. Novitasari W, Khotimah N. Dampak Penggunaan Gadget Terhadap Interaksi Sosial Anak Usia 5-6 Tahun. PAUDs Teratai. 2016;5:182-6.

3. Sari TP, Mitsalia AA. Pengaruh Pengguna Gadget Terhadap Personal Sosial the Effectofthe Use Of Gadgets to Personal Social ( TKIT ) of AL Mukmin. Profesi. 2016;13(2):72-8.

4. Radliya NR, Apriliya S, Zakiyyah TR. Pengaruh Penggunaan Gawai terhadap Perkembangan Sosial Emosional Anak Usia Dini. PAUD Agapedia. 2017;1(1):112.

5. Rideout V. Media and Technology in the Live of Infants and Toddlers. J ZERO TO THREE Natl Cent Infants, Toddlers Fam. 2013;33(4):1-56.

6. Triastutik Y, Nawangsari, H Maunaturrohmah A. Hubungan Bermain Gadget dengan Tingkat Perkembangan Anak Usia 4-6 Tahun. Profesi. 2018;7(1):1-9.

7. Gunawa MAA. Hubungan Durasi Penggunaan Gadget Terhadap Perkembangan Sosial Anak Prasekolah di TK PGRI 33 Sumurboto Banyumanik. Semarang: 
Universitas Diponegoro Kementrian Komunikasi dan Informasi Republik Indonesia. Jakarta: Indonesia Raksasa Teknologi Digital Asia; 2017.

8. American Academy of Pediatrics. Announces New Recommendations for Children's Media Use. J Pediatr. 2016;

9. Sucipto, Huda N. Pola Bermain Anak Usia Dini di Era Gadget Siswa PAUD Mutiara Bunda Sukodono Sidoarjo. PAUD Agapedia. 2016;1(1).

10. Hidayati E. Hubungan Pengetahuan Ibu Tentang Perkembangan Psikomotor Anak Usia 3-5 Tahun Di Desa Sarirejo Kec. Guntur Kab. Demak. J Keperawatan. 2011;1(2):12-22.

11. Wong DL, Hockenberry-Eaton, M Wilson D, Winkelstein LM, Schwartz P. Buku Ajar Keperawatan Pediatrik (Edisi 6). Jakarta: EGC; 2010.

12. Trinika Y, Nurfianti A, Abror I. Pengaruh Penggunaan Gadget Terhadap Perkembangan Psikososial Anak Usia Prasekolah (3-6 Tahun) di TK Swasta Kristen Immanuel Tahun Ajaran 2014-2015. Naskah Publ. 2015;

13. Alia T. Pendampingan Orang Tua pada Anak Usia Dini dalam Penggunaan Teknologi Digital. A J Languege, Lit Cult Educ. 2018;14(1):65-78.

14. Raihana PA, Wulandari W. Status dan Pengaruhnya dalam Kecerdasan Anak Prasekolah. J Indig. 2016;1(2):62-70.

15. Park G, Moon G, Yang D. The Moderation Effect of Smart Phone Addiction in Relationship between Self-Leadership and Innovative Behavior. World Acad Sci Eng Technol Int J Econ Manag Eng. 2016;8(5):1307-1310.

16. Sujianti. Hubungan Lama dan Frekuensi Penggunaan Gadget dengan Perkembangan Sosial Anak Prasekolah di TK Islam Al Irsyad o1 Cilacap. Kebidanan. 2018;8(1):54-65.

17. Heni, Mujahid AJ. Pengaruh Penggunaan Smartphone Terhadap Perkembangan Personal Sosial Anak Usia Pra-Sekolah. J Keperawatan Silampari. 2018;2(1):330-42.

18. Izzaty ER. Perilaku Anak Prasekolah. Jakarta: Elex Media Komputindo; 2017.

19. Kharmina N. Hubungan Antara Tingkat Pendidikan Orang Tua dengan Orientasi Pola Asuh Anak Usia Dini. J Keperawatan. 2011;1(2).

20. Ndari SS, Vinayastri A, Masykuroh K. Metode Perkembangan Sosial Emosi Anak Usia Dini. Tasikmalaya: Edu Publisher; 2019. 